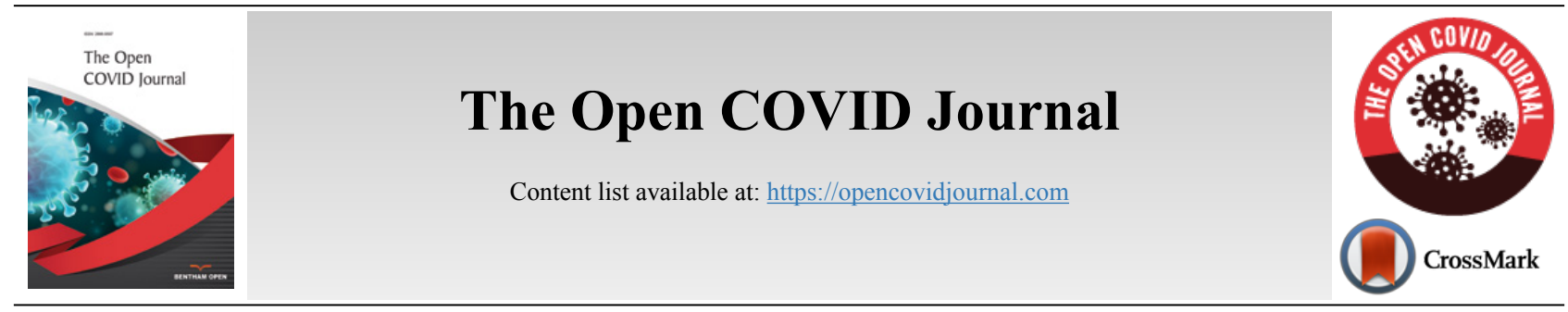

\title{
PERSPECTIVE
}

\section{Patent Insight into the Development of Therapeutic Strategies against Coronaviruses}

\author{
Hai-Long Zhang ${ }^{1, *}$, Ai-Feng Zhou ${ }^{1}$ and Yiqian $\mathrm{Li}^{2}$ \\ ${ }^{1}$ Central International Intellectual Property (Baotou) Co., Ltd, Baotou, 014030, China \\ ${ }^{2}$ Department of Building Services Engineering, The Hong Kong Polytechnic University, Kowloon, Hong Kong, China
}

\begin{abstract}
:
Coronaviruses are a group of RNA viruses, which cause diseases in humans. The emergence of COVID-19, has caused a global pandemic. It is focused on developing an effective therapeutic strategy against COVID-19. To better understand the development and evolution of therapeutic strategies against coronaviruses, we conducted US granted patents analysis. The results showed vaccines played a leading role in therapies against coronaviruses. Both attenuated vaccines and recombinant genetic vaccines were very important approaches in vaccine development against coronaviruses. It is not a rapid approach to develop peptide drugs against COVID-19 or future novel coronaviruses. The study was the first one to show the development and evolution in therapeutic strategies against coronaviruses based on patent insight. The present study provides a new insight into the development of therapeutic strategies against coronaviruses.
\end{abstract}

Keywords: Vaccines, Coronaviruses, Patent, Therapeutic strategy, Patent analysis, COVID-19, Diseases.

\begin{tabular}{|l|l|l|l|}
\hline Article History & Received: March 3, 2021 & Revised: May 25, 2021 & Accepted: June 21, 2021 \\
\hline
\end{tabular}

\section{INTRODUCTION}

Coronaviruses are a group of RNA viruses, which cause diseases in cats, dogs, and humans, resulting in respiratory tract infections [1 - 3]. Most infections caused by human coronaviruses are relatively mild, e.g., the common cold. However, some lethal coronaviruses can cause severe diseases [4]. For example, lethal coronaviruses of Severe Acute Respiratory Syndrome (SARS) caused by SARS-CoV in 2003 [5], and Middle East Respiratory Syndrome (MERS) caused by MERS-CoV in 2012 [6,7], as well as recently identified Coronaviruses Disease 2019 (COVID-19) caused by severe acute respiratory syndrome coronavirus 2 (SARS-CoV-2) [8, 9]. The coronaviruses can make people sick, and its symptoms include a runny nose, cough, sore throat. However, COVID-19 shows diversity in symptoms than ordinary coronaviruses, and it seems to spread more easily than SARS [10 - 14].

The emergence of COVID-19 has caused a global pandemic [15]. It is necessary on developing an effective therapeutic strategy against COVID-19. Currently, both attenuated vaccines and recombinant genetic vaccines are important approaches against coronaviruses. However, it is still unclear which approach is better to against coronaviruses. Thus, it is significant to provide evidence to show which

\footnotetext{
Address correspondence to this author at the Central International Intellectual Property (Baotou) Co., Ltd, Baotou, 014030, China;

E-mail: ipatenti@outlook.com
}

approach is better to against COVID-19 to help scientists rapidly develop therapeutic strategies. In addition, it is also significant to understand evolution in therapeutic strategy against coronaviruses. The article provides development, evolution, and new insight into therapeutic strategy against coronaviruses by patent evidence.

To better understand the development and evolution of therapeutic strategy against coronaviruses, we conducted US granted patents analysis. International Patent Classification (IPC) subclasses A61K39/215 (covering coronaviridae) were used for search. All patent publications from January 1953 to January 2021 were retrieved. The patent documents were searched by using International Patent Classification in the Patsnap system. The Patsnap software was used for analysis.

\section{PATENT FILING PROFILE}

We identified 249 US granted patent documents in the coronaviruses area. Patent filings surrounding coronaviruses had shown an increase trend since 1991. There were three "peaks" for published patents in the period 1953-2021. The three "peak" in the patent-filing profile were occurred in 1995, 2004, and 2015, respectively. As showed in Fig. (1), published patents surrounding coronaviruses reached an all-time high in 1995, with the number of published patent documents up to 25 . The patent-filing activity was obviously in the period 1993-2019 IP filings surrounding the coronaviruses area have 
been relatively steady at approximately 5 documents per year since 1993. The total number of patent documents filing in 1995, 2004, and 2015 accounted for about $23 \%$ of all patent documents.

\section{PATENT DISTRIBUTION}

There are about 100 assignees in all the patents and approximately $44 \%$ of the filings were by top 10 assignees. Intervet is the most prolific assignee with a number of 23 patent documents. Intervet accounts for approximately $9 \%$ of all patent documents. As shown in Fig. (2), Intervet is the leader in the number of patents, followed by Wyeth and Merial. Among the top 10 assignees, 8 assignees are companies, and 2

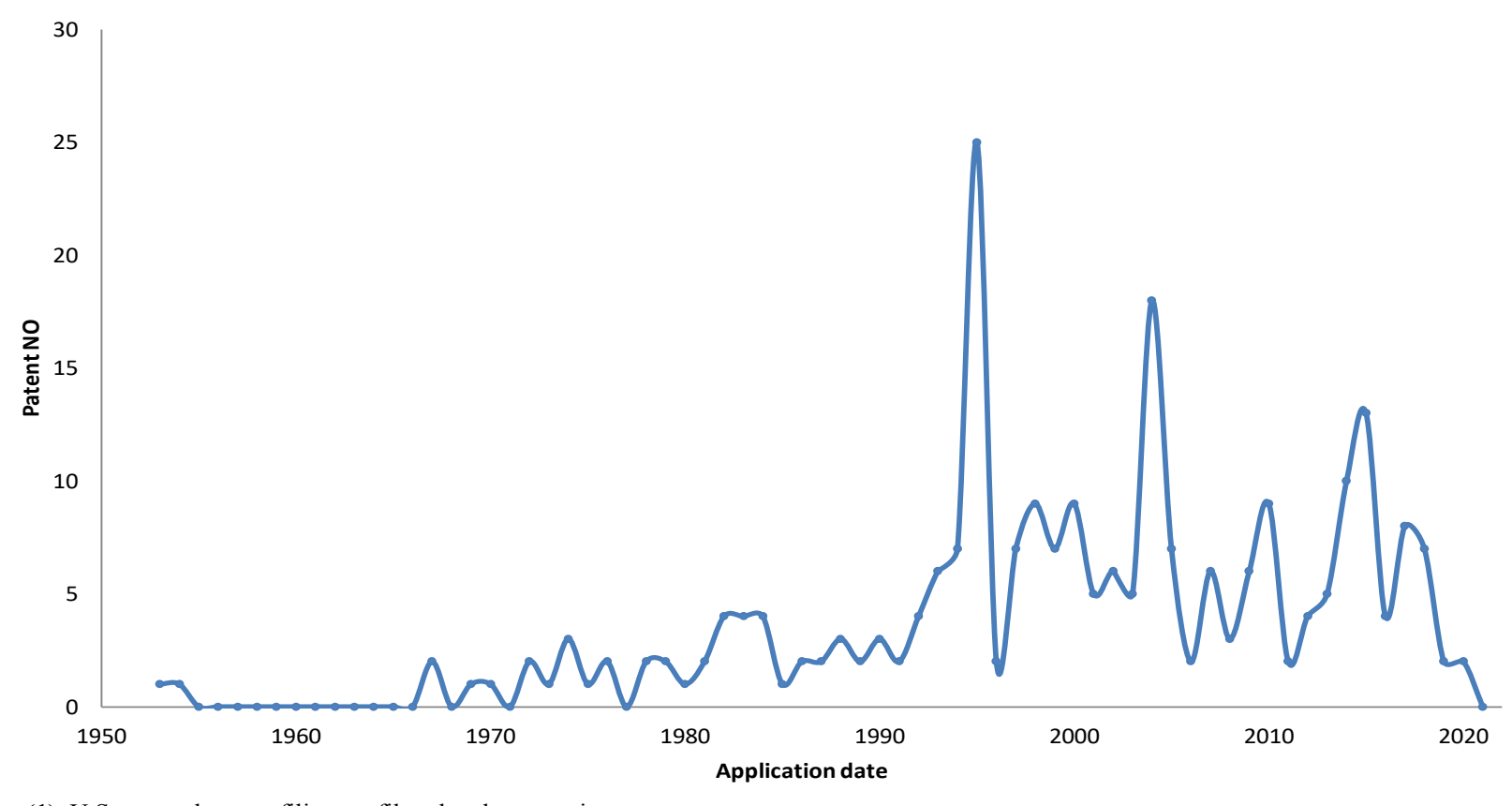

Fig. (1). U.S. granted patent-filing profile related coronaviruses.

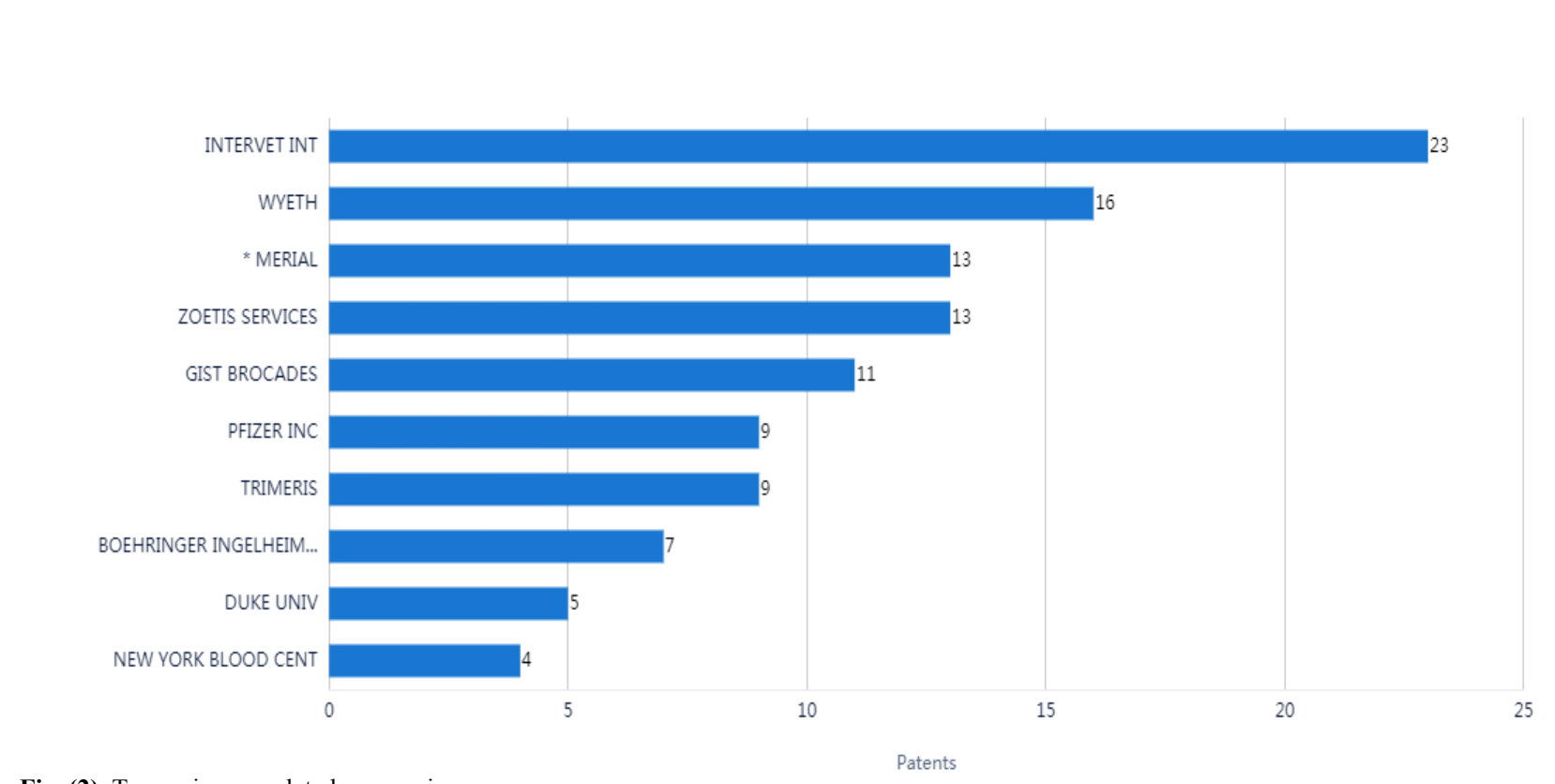

Fig. (2). Top assignees related coronaviruses.

assignees were research institutions. As the largest assignee, Intervet IP had 5 US patents which had family patents in China. Zoetis is the largest assignee in family patents, which had 9 family patents in China.

There were 5 assignees which the numbers of patents were more than 10 . The analysis showed that the ten leading assignees of patents surrounding coronaviruses were almost from small or medium companies. Examining the timing and patent assignees, most of the assignees demonstrated continuous prolific patents in the period 2002 -2021 (Fig. 3). Zoetis is an applicant which keeps very steady in the number of patents over past 20 years.

\footnotetext{
Fig. (2). Top assignees related coronaviruses.
} 


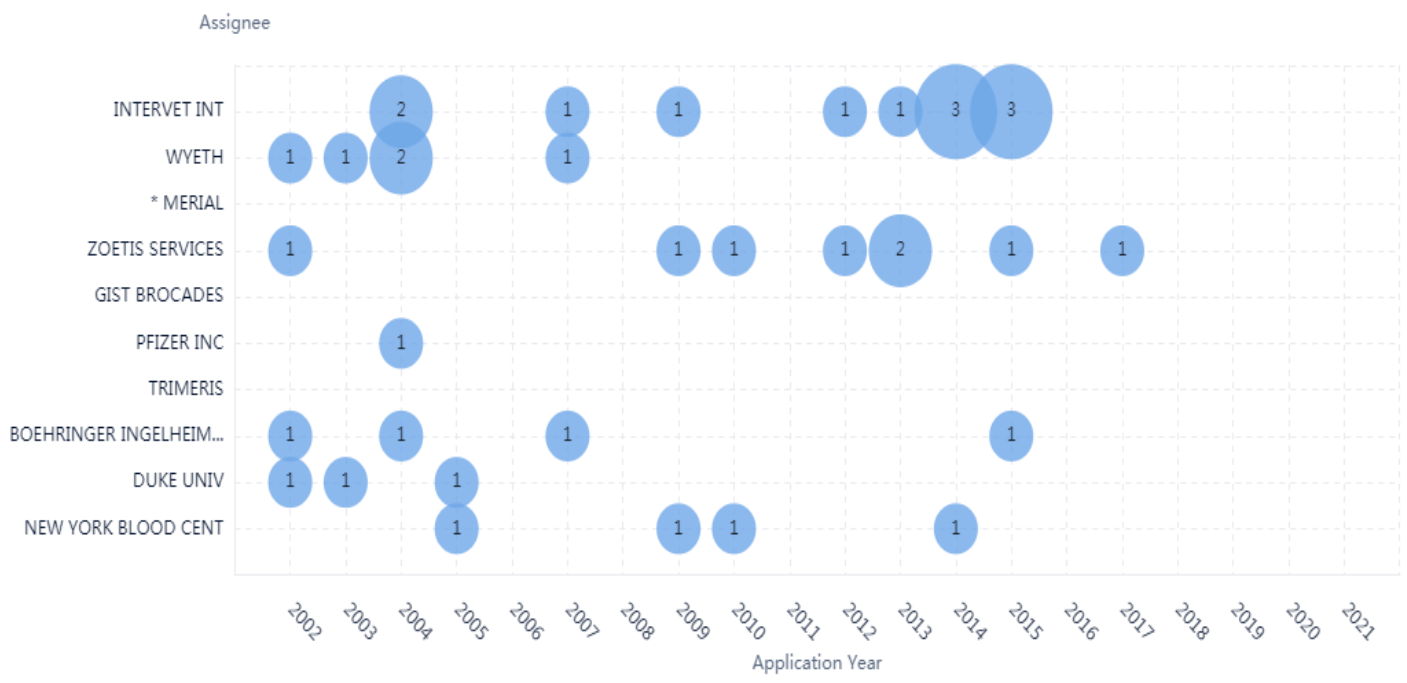

Fig. (3). Top assignees evolution of related coronaviruses.

\section{TECHNOLOGY AREAS}

As shown in Fig. (4), all the IPC are related to vaccines, antibody or peptides, For example, IPC of C07K14, C12N15, $\mathrm{C} 12 \mathrm{~N} 7, \mathrm{C} 12 \mathrm{P} 21$, and $\mathrm{C} 07 \mathrm{~K} 16$, all of which were related to the vaccine or antibody technologies. As showed in Fig. (5), the
Evolution analysis of IPC showed that the number of patents was in a stable stage between 2002 and 2020. It showed that the majority of the therapies against coronavirus were focused on the vaccine, which reflects the focus on therapeutic strategy. Recently granted patents against coronaviruses were shown in Table $\mathbf{1 .}$

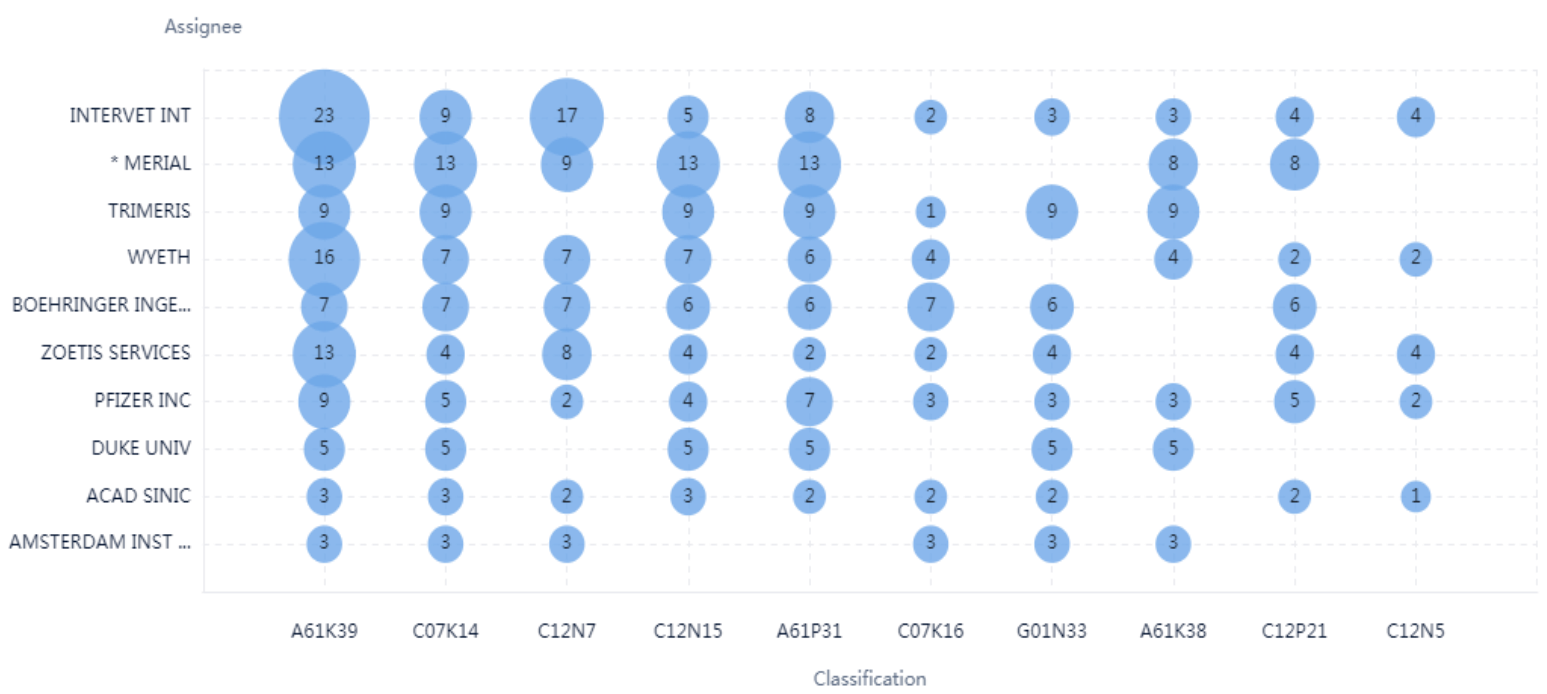

Fig. (4). The analysis of top assignees and IPC.

Table 1. Recent patents against coronaviruses.

\begin{tabular}{|c|c|c|c|}
\hline Publication Number & Title & Application Date & Current Assignee \\
\hline US10821172B2 & Vaccine composition and preparation method and use thereof & $2017-11-03$ & Pulike Biological Engineering, Inc. \\
\hline US10660854B2 & $\begin{array}{c}\text { Thermostable vaccines based on ether lipids and native viral } \\
\text { envelope proteins }\end{array}$ & $2017-11-15$ & Batavia Biosciences Inc. \\
\hline US10117929B1 & $\begin{array}{c}\text { Nucleic acid-based adjuvant and porcine vaccine composition } \\
\text { including the same }\end{array}$ & $2017-11-23$ & $\begin{array}{c}\text { National Pingtung University Of Science } \\
\text { And Technology }\end{array}$ \\
\hline US10329538B2 & $\begin{array}{c}\text { Live attenuated Arkansas serotype infectious bronchitis virus } \\
\text { vaccine }\end{array}$ & $2018-01-26$ & $\begin{array}{c}\text { University Of Georgia Research } \\
\text { Foundation, Inc. }\end{array}$ \\
\hline
\end{tabular}


(Table 1) contd....

\begin{tabular}{|c|c|c|c|}
\hline Publication Number & Title & Application Date & Current Assignee \\
\hline US10130702B2 & Vaccine composition and preparation method and use thereof & 2018-01-31 & Pulike Biological Engineering, Inc. \\
\hline US10702601B2 & Porcine epidemic diarrhea virus vaccine & 2018-03-14 & $\begin{array}{l}\text { Boehringer Ingelheim Animal Health Usa } \\
\text { Inc. }\end{array}$ \\
\hline US10548971B2 & MERS-CoV vaccine & 2018-06-29 & $\begin{array}{c}\text { The Trustees Of The University Of } \\
\text { Pennsylvania | Inovio Pharmaceuticals, Inc. }\end{array}$ \\
\hline US10772953B2 & $\begin{array}{l}\text { Recombinant spike ectodomain proteins, compositions, } \\
\text { vectors, kits, and methods for immunizing against avian } \\
\text { infectious bronchitis virus }\end{array}$ & 2018-08-09 & Auburn University \\
\hline US10213509B2 & Reduced foaming vaccine compositions & 2018-09-10 & Abic Biological Laboratories Ltd. \\
\hline US10849972B2 & $\begin{array}{l}\text { Trimeric S1-CD40L fusion protein vaccine against Middle } \\
\text { East respiratory syndrome-coronavirus }\end{array}$ & 2018-11-27 & King Abdulaziz University \\
\hline US10610596B2 & $\begin{array}{l}\text { Methods of making solid vaccine compositions having } \\
\text { reduced foaming }\end{array}$ & 2019-01-24 & Abic Biological Laboratories Ltd. \\
\hline US10759846B2 & $\begin{array}{l}\text { Middle east respiratory syndrome coronavirus immunogens, } \\
\text { antibodies, and their use }\end{array}$ & $2019-05-03$ & $\begin{array}{c}\text { The United States Of America, As } \\
\text { Represented By The Secretary, Department } \\
\text { Of Health And Human Services }\end{array}$ \\
\hline US10905758B2 & Intranasal vector vaccine against porcine epidemic diarrhea & 2019-09-18 & Boehringer Ingelheim Vetmedica Gmbh \\
\hline US10702600B1 & Betacoronavirus mRNA vaccine & $2020-02-28$ & Modernatx, Inc. \\
\hline US10806784B1 & Composition and method for treating MERS & $2020-08-06$ & King Abdulaziz University \\
\hline
\end{tabular}

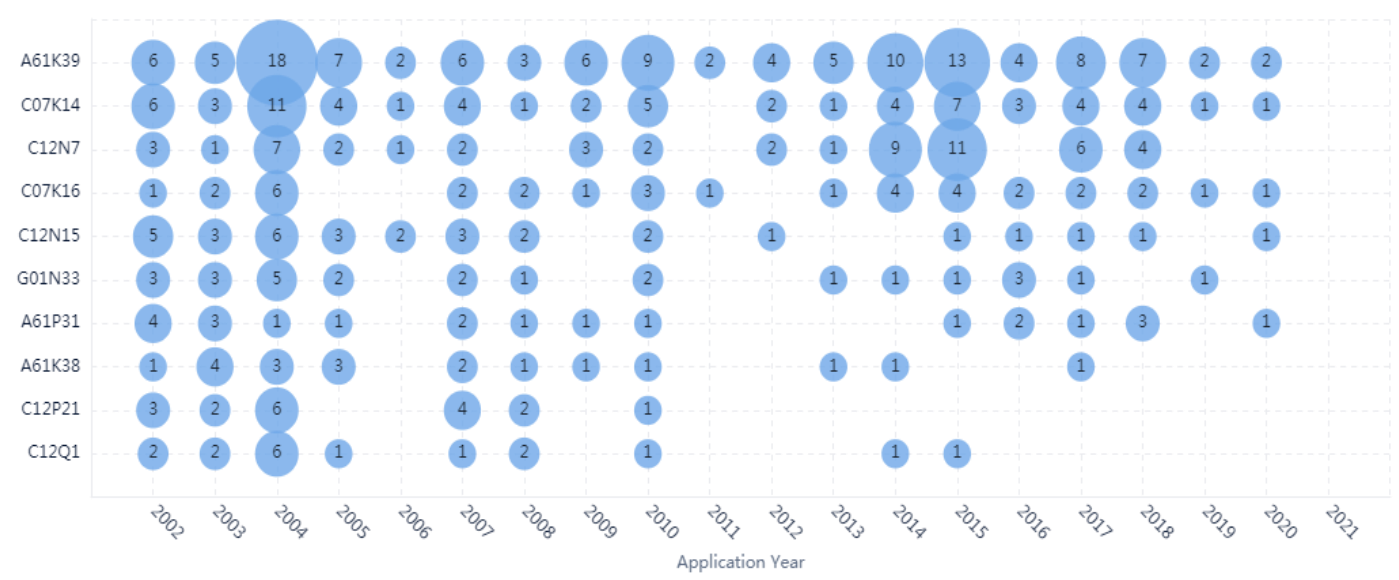

Fig. (5). IPC evolution related coronaviruses.

Examining the timing and technical content of a company's IP filings provides valuable insight into their strategy in therapies against coronaviruses. Companies have varied positions within the therapies against coronaviruses. Intervet IP focused on vaccine technologies in both attenuated vaccines containing attenuated infectious bronchitis virus and in recombinant genetic vaccines containing recombinant manipulation vaccine. Merial IP mainly focused on the development of recombinant genetic vaccines, while Trimerish was highly specialized in direct peptides containing potent antiretroviral activity.
The patent 3D landscape provides an overview of the patents of technologies against coronaviruses. The number of patents was showed by dots, and the patent documents with similar contents were delineated by contour lines. The white "peaks" represent areas having the most in the number of patent areas. There were three major "peaks" in the patent 3D landscape. As showed in Fig. (6), "Peak 1" represented those patent documents with traditional attenuated vaccines, "Peak 2 " represented those patent documents with represented genetic recombinant vaccines, and "Peak 3" showed those patent documents about peptides with antifusogenic and antiviral activities. 


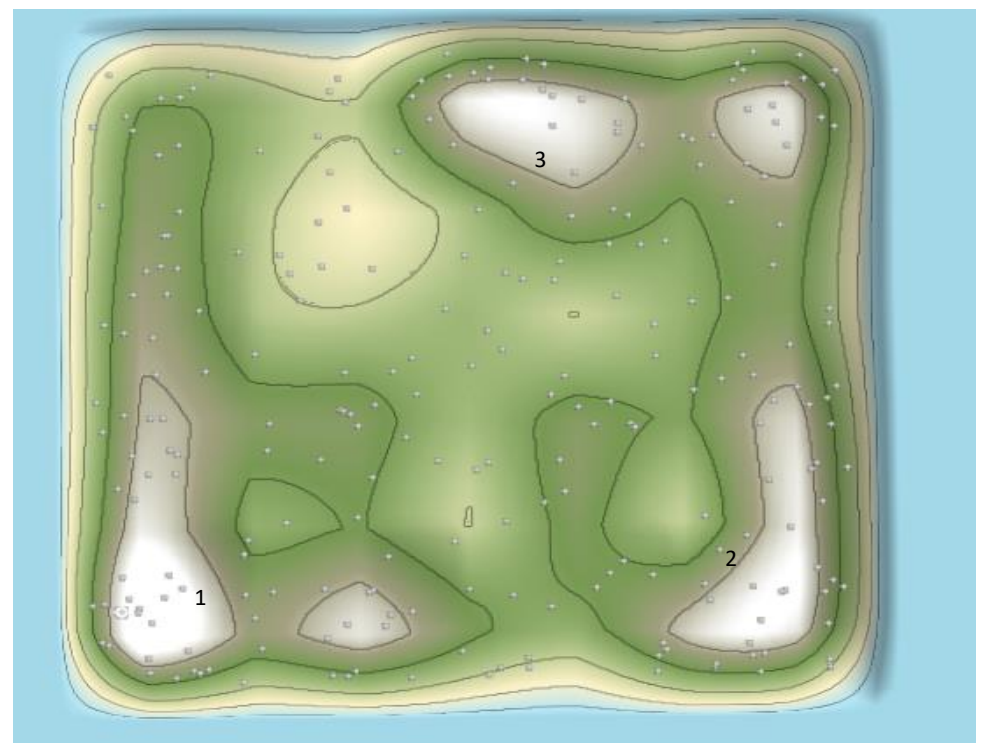

Fig. (6). Current 3D Landscaping related coronaviruses.

Examining the timing and 3D landscape of IP filings provides valuable insight into their therapeutic development against coronaviruses. We analyzed three periods in the 3D landscape. As showed in Figs. (7 and 8), only "Peak 1" was formed in the 3D landscape before 1992, which indicated that attenuated vaccine was a major trend in therapeutic development before 1992 and there were almost no genetic recombinant vaccines against coronavirus before 1992. The recombinant genetic vaccines against coronavirus were starting appeared in the period 1992-1998, which indicated recombinant genetic vaccines against coronavirus were rapidly developed after 1992. Patents surrounding peptides were starting developed in 1995.

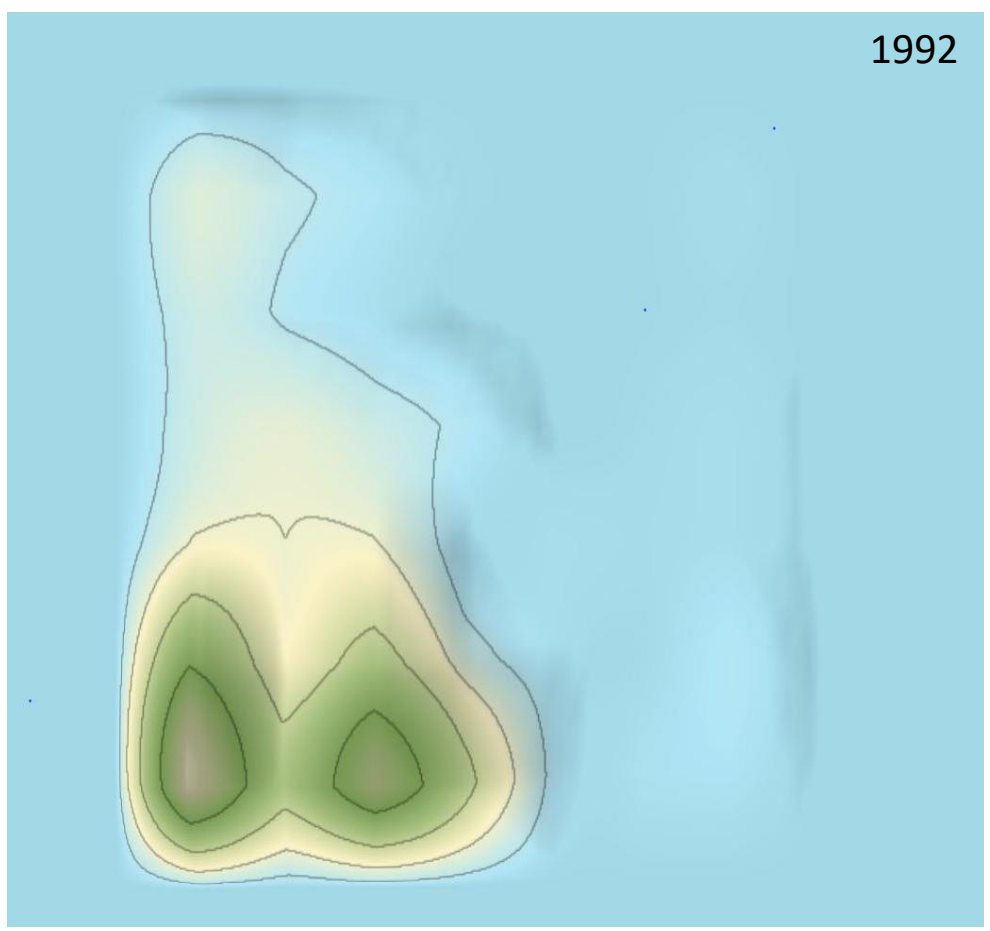

Fig. (7). 3D Landscaping before 1992. 


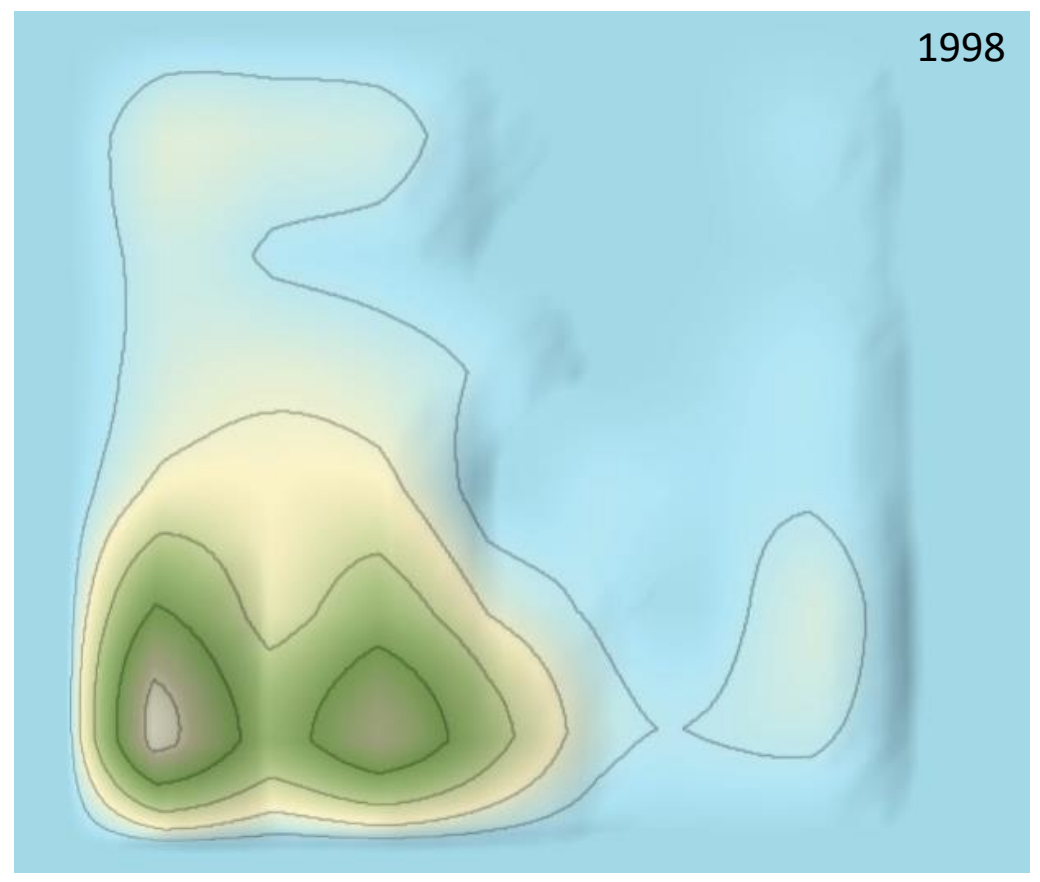

Fig. (8). 3D Landscaping before 1998.

\section{RESULTS AND DISCUSSION}

There were three "peaks" for published patent documents in the period 1953-2021. The Year of 1995 was a patent-filing activity year, which may contribute new technology development in recombinant genetic vaccine. The emergence of new technology can promote rapid patent filings. The second patent-filing activity year was in 2004, which may be due to the pandemic of SARS in 2003. The outbreak of SARS resulted in a significant increase in the number of patients. The third patent-filing activity year was in 2015 , which may be due to the outbreak of MERS. The patent-filing activity against coronavirus is correlated with pandemic and the emergence of new technologies. The significant feature of patent-filing surrounding coronavirus is obviously periodic, which may relate with the periodic occurrence of pandemics in coronaviruses.

The 3D landscape of IP filings provides valuable insight into their therapeutic development against coronaviruses. The results showed the preliminary strategy was to develop attenuated vaccines. The subsequent strategy was to develop recombinant genetic vaccines to against coronaviruses. A recent developing strategy was to develop peptides against coronaviruses. Currently, those three strategies are coexisted in therapies against coronaviruses, as showed in Figs. (7 and 8).
However, vaccines including attenuated vaccines and recombinant genetic vaccines were dominant in therapy against coronaviruses. Polypeptides played only a minor role in therapies against coronaviruses. The analysis showed that the top leading assignees of patents surrounding coronaviruses were basically from small or medium companies. This is significantly different with research and development in anticancer drugs. Most of anti-cancer drugs is developed by large global pharmaceutical companies.

The 3D landscape showed that vaccines played a major role in therapy against coronaviruses. Evolution 'maps' in therapeutic development against coronaviruses were showed by the timeline in the 3D landscape. Genetic recombinant vaccines were rapidly developed in the past 20 years, which accounted for approximately half of all the technologies in vaccines. As showed in Fig. (9), Word cloud analysis showed words of "vaccine composition", "immune response", were the highest frequent in use of all the patent documents. Word cloud indicated that vaccines were a vital approach in therapeutic development against coronaviruses, which was corresponding to the analysis of the patent 3D landscape. Base on the patent analysis of recent development in therapies against coronaviruses, the results indicated that vaccines play a leading role in therapies against coronaviruses. 


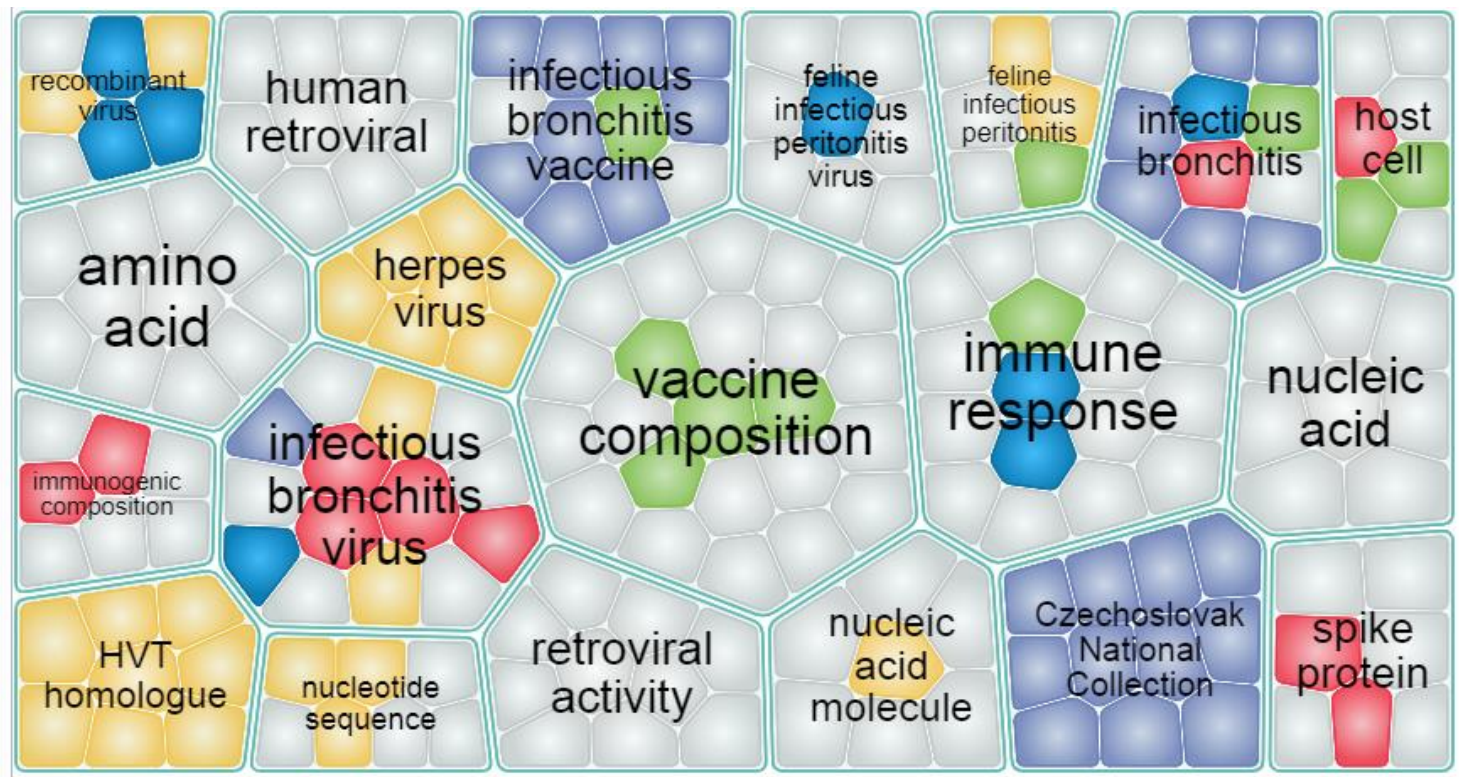

Fig. (9). The Word Cloud analysis related coronaviruses.

\section{CONCLUSION}

The study was the first time to show the development in therapeutic strategies against coronaviruses based on patent insight. Currently, vaccines play a leading role in therapies against coronaviruses. Both attenuated vaccines and recombinant genetic vaccines are a very important approach in vaccine development against coronaviruses. The peptide molecules may open new windows in therapy against coronaviruses. However, an effective and rapid method to develop a therapeutic strategy against coronaviruses or COVID-19 is to develop vaccines. It is not a rapid approach to develop peptide drugs against COVID-19 or future novel coronaviruses. Our study is the first time to show developing evolution 'map' in therapeutic strategies against coronaviruses by the $3 \mathrm{D}$ landscape. The present study provides significant insight for rapidly developing therapeutic strategies against COVID-19.

\section{CONSENT FOR PUBLICATION}

Not applicable.

\section{FUNDING}

None.

\section{CONFLICT OF INTEREST}

The authors confirm that this article content has no conflict of interest.

\section{ACKNOWLEDGEMENTS}

Declared none.

\section{REFERENCES}

[1] Elshabrawy HA. SARS-CoV-2: An update on potential antivirals in light of SARS-CoV antiviral drug discoveries. Vaccines (Basel) 2020;
8(2): 8 .

[http://dx.doi.org/10.3390/vaccines8020335] [PMID: 32585913]

[2] Yang N, Shen HM. Targeting the endocytic pathway and autophagy process as a novel therapeutic strategy in COVID-19. Int J Biol Sci 2020; 16(10): 1724-31.

[http://dx.doi.org/10.7150/ijbs.45498] [PMID: 32226290]

[3] Tizard IR. Vaccination against coronaviruses in domestic animals Vaccine 2020; 38(33): 5123-30.

[http://dx.doi.org/10.1016/j.vaccine.2020.06.026] [PMID: 32563608]

[4] Alturki SO, Alturki SO, Connors J, et al. The 2020 pandemic: Current SARS-CoV-2 vaccine development. Front Immunol 2020; 11: 1880. [http://dx.doi.org/10.3389/fimmu.2020.01880] [PMID: 32973779]

[5] Bhatti A ur R, Zreik J, Yolcu YU, Alvi MA, Abode-Iyamah K, Quinones-Hinojosa A. Nervous system involvement in SARScoronavirus infection: a review on lessons learned from the previous outbreaks, ongoing pandemic and what to expect in the future. Int $\mathrm{J}$ Neurosci 2020; 1-10.

[6] Farooq HZ, Davies E, Ahmad S, et al. Middle East Respiratory Syndrome Coronavirus (MERS-CoV) - Surveillance and testing in North England from 2012 to 2019. Int J Infect Dis 2020; 93: 237-44. [http://dx.doi.org/10.1016/j.ijid.2020.01.043] [PMID: 32004690]

[7] Azhar EI, Hui DSC, Memish ZA, Drosten C, Zumla A. The Middle East Respiratory Syndrome (MERS). Infect Dis Clin North Am 2019; 33(4): 891-905.

[http://dx.doi.org/10.1016/j.idc.2019.08.001] [PMID: 31668197]

[8] Azer SA. COVID-19: pathophysiology, diagnosis, complications and investigational therapeutics. New Microbes New Infect 2020; 37100738

[http://dx.doi.org/10.1016/j.nmni.2020.100738] [PMID: 32834902]

[9] Armocida D, Palmieri M, Frati A, Santoro A, Pesce A. How SARSCov-2 can involve the central nervous system. A systematic analysis of literature of the department of human neurosciences of Sapienza University, Italy. J Clin Neurosci 2020; 79: 231-6.

[http://dx.doi.org/10.1016/j.jocn.2020.07.007] [PMID: 33070902]

[10] El-Anwar MW, Elzayat S, Fouad YA. ENT manifestation in COVID-19 patients. Auris Nasus Larynx 2020; 47(4): 559-64. [http://dx.doi.org/10.1016/j.anl.2020.06.003] [PMID: 32586739]

[11] Williams VR, Pajak D, Salt N, Leis JA. Clinical presentation and outcomes of long-term care residents with coronavirus respiratory infection: A retrospective cohort study. Open Forum Infect Dis 2448; 6: S846-6.

[http://dx.doi.org/10.1093/ofid/ofz360.2126]

[12] Zeidler A, Karpinski TM. SARS-CoV, MERS-CoV, SARS-CoV-2 comparison of three emerging coronaviruses. Jundishapur J Microbiol $2020 ; 13$ e103744 
[http://dx.doi.org/10.5812/jjm.103744]

[13] Abbasi M. The novel coronavirus: A major global health concern. J Infertil Reprod Biol 2020; 8: 1-5.

[14] Biadsee A, Biadsee A, Kassem F, Dagan O, Masarwa S, Ormianer Z. Olfactory and oral manifestations of COVID-19: Sex-related symptoms-A potential pathway to early diagnosis. Otolaryngol Head
Neck Surg 2020; 163(4): 722-8

[http://dx.doi.org/10.1177/0194599820934380] [PMID: 32539587]

[15] Mahajan K, Chandra KS. Cardiovascular comorbidities and complications associated with coronavirus disease 2019. Med J Armed Forces India 2020; 76(3): 253-60

[http://dx.doi.org/10.1016/j.mjafi.2020.05.004] [PMID: 32773926]

\section{(C) 2021 Zhang et al.}

This is an open access article distributed under the terms of the Creative Commons Attribution 4.0 International Public License (CC-BY 4.0), a copy of which is available at: https://creativecommons.org/licenses/by/4.0/legalcode. This license permits unrestricted use, distribution, and reproduction in any medium, provided the original author and source are credited. 